\title{
A Response to Michael Spitzer's Commentary
}

\author{
IMRE LAHDELMA[1] \\ Department of Music, Durham University, UK \\ TUOMAS EEROLA \\ Department of Music, Durham University, UK
}

\begin{abstract}
The authors respond to the commentary by Michael Spitzer which appeared in Vol. 14, No. 1-2 of Empirical Musicology Review. The response 1) points out the problem with equating nostalgia and tension in the perception of single chords, 2) makes a case for why studying the role of vertical harmony, isolated from other musical cues, is insightful, and 3) questions the relevance of appoggiaturas as an explanation for the perception of nostalgia in single chords.
\end{abstract}

Submitted 2019 December 6; accepted 2020 August 6.

Published 2020 October 22; https://doi.org/10.18061/emr.v15i1-2.7324

KEYWORDS: nostalgia, psychology, analysis, chord, vertical harmony, ontology

WE are delighted and invigorated by this eloquent commentary from an eminent music theorist on our paper discussing the relationship between vertical harmony and perceived emotional connotations. We value constructive dialogue between the disciplines of music psychology and analysis, and acknowledge that nostalgia conveyed by harmony perfectly intersects both disciplines.

In the first paragraph of his commentary, Spitzer (2019) successfully summarises the article by Lahdelma and Eerola (2015). What is worth emphasizing already here, however, is that the view that "the inclination of the dissonant interval to resolve to a triad tone (a tonic or the third degree) is expressive of the yearning or longing associated with nostalgia" (Spitzer, 2019, p. 87) is not the authors' own, but a theory put forward by musicologist Deryck Cooke (1959). This theory's adequacy in explaining perceived nostalgia in the major seventh chord is criticised from various angles by Lahdelma and Eerola (2015) in the article's 'Intrinsic Emotional Meaning Built Into Tonality' section (pp. 250-251).

The theoretical inclination of the dissonant interval to a triad is echoed in Spitzer's first main criticism levelled against Lahdelma and Eerola (2015):

...processes of tension and resolution are much more generic and fundamental than can be captured by a single emotional category. In other words, tension is a dimension, whereas nostalgia is a category. (p. 87)

First, it is contentious whether nostalgia is indeed a category and not a dimension (see Barrett et al., 2010). Second, what is vitally important to note here is that Lahdelma and Eerola (2016a) demonstrated in an empirical study (on which their 2015 theoretical paper was based) that tension in fact does not drive the perception of nostalgia. Their data showed a complete lack of correlation $(r=.11)$ between nostalgia and tension. In other words, automatically equating nostalgia and tension is arguably a red herring here: perceived nostalgia in single chords is not linked to tonal tension but is either learnt by sheer association through, for example, film music (see Juslin 2019), or is mediated by some other psychological mechanism, such as the theory coined by Lahdelma and Eerola (2015) and introduced in the article's "Clashing Conventions" section (pp. 251-256). This theory steers clear of the question of tonal tension and tackles the issue, to quote the original article:

from another perspective than Cooke's (1959) suggestion of 'iconic' meaning arising from tonal tension which attributes the leading tone a special 'affective quale' (cf. Huron, 2006) in relation to the tonic. (p. 251) 
To summarise, the "Clashing Conventions" theory by Lahdelma and Eerola (2015) proposes that the clashing of two highly conventionalized indices in Western culture (the major triad as an index of happiness and the minor second/major seventh intervals as indices of negative valence and sadness) might create new emotional meaning that is perceived as the complex emotion of nostalgia without designating any special role to the seventh tone's tendency towards the tonic (cf. Cooke, 1959).

Spitzer's second main criticism against Lahdelma and Eerola (2015) is the question of musical cues working together in conveying complex emotions such as nostalgia. In his view, "what determines the emotion is the collateral parameters of tempo, texture, dynamics, and articulation through which tension is elaborated" (Spitzer, 2019, p. 87). The rationale for the original empirical study by Lahdelma \& Eerola (2016a) was to deliberately remove these cues in order to attribute emotional qualities, as much as possible, to the effects of actual vertical harmony, instead of the interaction between harmony and other parameters. Had the original data included other psychophysical parameters as well, the role of harmony would most likely have remained unclear. As for Spitzer's concern about whether "Lahdelma and Eerola's subjects would have heard 'nostalgia' if the 7th chords were performed loudly and staccato" (p. 87), the important role of psychophysical cues such as amplitude and expression was in fact acknowledged by Lahdelma and Eerola (2015, p. 257):

Naturally, far from being a completely 'fixed' and 'lexical' meaning of nostalgia and longing, the major seventh chord is obviously subordinate to psychophysical (tempo, dynamics, phrasing) parameters as well, especially in actual music - just like the major and minor triads with regard to 'happiness' and 'sadness', respectively (Gabrielsson \& Lindström, 2010).

That said, this does not exclude the possibility of adding more naturalistic content into future studies addressing this question; it is worth keeping in mind, however, that with 90 years of empirical research we have quite a solid understanding of how musical cues work together to convey emotions (for an overview, see Juslin \& Lindström, 2010), but we do not have insight into whether the cues in isolation are capable of conveying emotions.

The issues and counterarguments raised above reflect the fundamental ontological difference between music history/analysis and music psychology; the former relies on fine-grained subjective insight whereas the latter gains knowledge from systematic empirical observations (see Marsden, 2012), usually guided by theory and organised in the form of experiments or corpus analysis. In our view, both stances have the potential to deliver meaningful insights to this research topic. Ongoing discussion between the two is perhaps the best way to ensure that any progress incorporates a sensitivity to the nuances indicated by musicologists with the systematic rigour and control espoused by music psychology. The latter will rely on reductionism, which tends to be an easy target of criticism, but does allow us to disentangle complex issues and identify the exact contribution of individual elements in this process. With this topic, we have taken the reductionism to one extreme (single chords), and sacrificed musical context and other parameters of emotional expression. Nevertheless, in doing so we are able to demonstrate that chords by themselves lead to coherent patterns of emotional expressions by participants when using self-reports. Another strong indicator that single chords convey emotional information has been demonstrated with affective priming studies, where participants consistently evaluate semantic target stimuli (words) faster when primed with emotionally congruent chords (see e.g., Steinbeis \& Koelsch, 2011).

The third main criticism offered by Spitzer is that it might in fact be the general idiom of appoggiaturas conveying the emotion of nostalgia, rather than the major seventh chord specifically. As Spitzer reminds us, the emotional effect of appoggiaturas has indeed been discussed theoretically and has also been demonstrated empirically (Sloboda, 1991). The problem, however, is that this vehicle has not been empirically shown to specifically convey nostalgia, and hence assumptions about "nostalgic appoggiaturas" in the music of Gluck and Mozart should be taken with a pinch of salt. The appoggiatura idea proposed by Spitzer implies that the perception of nostalgia is in fact tension stemming from the pull of stable degrees (the tonic and the third) in the major mode framework through "acute dissonances of pervasive 1-7 and 4-3 appoggiaturas". As discussed previously, empirical findings with single chords show that tension and nostalgia are not related perceptual phenomena (Lahdelma \& Eerola, 2016a), while dissonance and tension in turn are virtually synonyms (Lahdelma \& Eerola, 2016b). In other words, while appoggiaturas would of course yield perceived tension, this tension would not necessarily be automatically perceived as nostalgic. Finally, if it were indeed the general idiom of appoggiaturas and not the major 
seventh chord itself conveying the emotion of nostalgia, then why is this particular chord frequently associated with nostalgia in popular music when it is present without appoggiaturas (see e.g., Everett, 2008)?

Unfamiliar music has been empirically shown to be able to trigger nostalgia (see Trost et al., 2012). Following from this, there seem to be certain intrinsic features in music that create nostalgic connotations in listeners - hence the question at hand is far from trivial for empirical musicology. While Spitzer's critical commentary on the paper of Lahdelma and Eerola (2015) offers important points to consider from an analytical point of view, in terms of empirical reality, they may fall short. After all, sometimes a cigar is just a cigar.

\section{ACKNOWLEDGEMENTS}

We would like to thank Thomas Magnus Lennie for constructive comments and additional references. This article was copyedited by Tanushree Agrawal and layout edited by Kelly Jakubowski.

\section{NOTES}

[1] Correspondence can be addressed to: Imre Lahdelma, Department of Music, Durham University, Palace Green, Durham DH1 3EP, UK. E-mail: imre.d.lahdelma@durham.ac.uk.

\section{REFERENCES}

Barrett, F., Grimm, K., Robins, R., Wildschut, T., Sedikides, C., \& Janata, P. (2010). Music-evoked nostalgia: Affect, memory, and personality. Emotion, 10, 390-403. https://doi.org/10.1037/a0019006

Cooke, D. (1959). The Language of Music. Oxford, UK: Oxford University Press.

Everett, W. (2008). The Foundations of Rock: From "Blue Suede Shoes" to "Suite: Judy Blue Eyes". New York: Oxford University Press.

Juslin, P. (2019). Musical Emotions Explained: Unlocking the Secrets of Musical Affect. Oxford, UK: Oxford University Press. https://doi.org/10.1093/oso/9780198753421.001.0001

Juslin, P., \& Lindström, E. (2010). Musical expression of emotions: Modelling listeners' judgements of composed and performed features. Music Analysis, 29(1-3), 334-364. https://doi.org/10.1111/j.1468-2249.2011.00323.x

Lahdelma, I., \& Eerola, T. (2015). Theoretical proposals on how vertical harmony may convey nostalgia and longing in music. Empirical Musicology Review, 10(3), 245-263. https://doi.org/10.18061/emr.v10i3.4534

Lahdelma I., \& Eerola, T. (2016a). Single chords convey distinct emotional qualities to both naïve and expert listeners. Psychology of Music, 44, 37-54. https://doi.org/10.1177/0305735614552006

Lahdelma, I., \& Eerola, T. (2016b). Mild dissonance preferred over consonance in single chord perception. i-Perception, 7(3), 1-21. https://doi.org/10.1177/2041669516655812

Marsden, A. (2012). Ontology, epistemology, and some research proposals. Journal of Mathematics and Music, 6(2), 161-167. https://doi.org/10.1080/17459737.2012.698157

Monelle, R. (2000). The Sense of Music. New Jersey: Princeton University Press.

Sloboda, J. (1991). Music structure and emotional response: Some empirical findings. Psychology of Music, 19, 110-120. https://doi.org/10.1177/0305735691192002 
Spitzer, M. (2019). Commentary on Lahdelma and Eerola. Empirical Musicology Review, 14(1-2), 87-88. https://doi.org/10.18061/emr.v14i1-2.5100

Steinbeis, N. \& Koelsch, S. (2011). Affective priming effects of musical sounds on the processing of word meaning. Journal of Cognitive Neuroscience, 23(3), 604-621. https://doi.org/10.1162/jocn.2009.21383

Trost, W., Ethofer, T., Zentner, M., \& Vuilleumier, P. (2012). Mapping aesthetic musical emotions in the brain. Cerebral Cortex, 22(12), 2769-2783. https://doi.org/10.1093/cercor/bhr353 